\title{
Do Brokers Act in the Best Interests of Their Clients? New Evidence from Electronic Trading Systems
}

\author{
Annilee M. Game * \\ Lecturer, Organisational Behaviour and Business Ethics \\ Norwich Business School \\ University of East Anglia \\ Norwich, NR4 7TJ \\ Tel: 44 (0) 1603591182 \\ A.Game@uea.ac.uk
}

\author{
Andros Gregoriou \\ Professor, Accounting and Finance \\ Hull University Business School \\ University of Hull \\ Hull, HU6 7RX
}

Tel: +44 (0) 01482463066

a.gregoriou@hull.ac.uk

*Corresponding Author

Word count: 5,220 


\title{
Do Brokers Act in the Best Interests of Their Clients? \\ New Evidence from Electronic Trading Systems
}

\begin{abstract}
Prior research suggests brokers do not always act in the best interests of clients, although morally obligated to do so. We empirically investigated this issue focusing on trades executed at best execution price, before and after the introduction of electronic limit order trading, on the London Stock Exchange. As a result of limit order trading, the proportion of trades executed at the best execution price for the customer significantly increased. We attribute this to a sustained increase in the liquidity of stocks as a result of limit-order trading, regardless of market capitalization. We discuss the ethical implications of our findings and conclude that market structures which enhance market competitiveness may help reconcile broker and client interests.
\end{abstract}

Keywords: Ethics of Brokers, Trade Execution, Limit Order Trading, Liquidity, Firm Size. 


\section{Do Brokers Act in the Best Interests of their Clients? New Evidence from Electronic Trading Systems}

\section{Introduction}

Continuing global economic uncertainty and recent revelations concerning the role of derivatives traders in fixing Libor interest rates (London inter-bank lending rate) (bbc.co.uk 2012) have heightened media and public scrutiny of the perceived short-term, profit driven behaviour of investment professionals. The ethical motivations and conduct of individuals who trade stocks on the financial markets are of particular interest. Given that stock brokers and traders are dealing with other people's money, they are expected to uphold the highest ethical standards in order to maintain public trust in the market system as a whole (Baker \& Veit 1998). Underpinning this psychological contract, stock brokers are obligated to execute trades on the financial markets with 'due regard' for the interests and fair treatment of their clients (FCA 2013). However, previous research suggests that brokers' personal goals and interests may sometimes override their obligations (e.g. Angel \& McCabe 2012, Battalio \& Loughran 2008). How to better align brokers' motivations and actions with investors' interests is therefore a key ethical concern, and the focus of the present study.

Based on evidence suggesting that stock brokers see little need for ethics in trading, and perceive ethical codes as an unnecessary constraint on the competitiveness of the financial markets (e.g. Norberg 2009), we argue that structural changes to the mechanisms for executing transactions in the markets may constitute an effective means of aligning brokers and investors' interests that can complement the development of ethical standards and ethical management practices. Specifically, because the electronic limit order trading system increases competition (via improved liquidity and informational transparency) we propose, consistent with Adam Smith's egoism (1981 [1776]), that it may help translate brokers' selfinterested inclinations into increased investor wealth. In order to investigate our hypothesis, 
we analysed data on the proportion of trades conducted at the 'best execution price' by stock brokers before and after the introduction of limit order trading on the London Stock Exchange (LSE).

The remainder of this paper is organized as follows: we begin with a brief overview of the relationship between stock brokers and investors, and brokers' obligations. Next we review existing theory and research regarding the ethical motivations and conduct of brokers. This is followed by a discussion of the role of liquidity in financial markets, and the transition to limit order trading as background to our study. We then describe the research context, before presenting our method and findings. We discuss our findings and their implications, and conclude in the final section.

\section{Agency and regulation in financial trading}

Investors gain access to the stock exchanges of the financial markets by instructing a broker to execute trades on their behalf. Effectively clients and brokers have a principal-agent relationship, although the degree to which the broker acts as the client's agent (versus principal) when trading/investing depends on client sophistication (i.e. investment experience) and their specific instructions (Angel \& McCabe 2012). Additionally, brokers/traders in the UK are employees of firms authorised by the Financial Conduct Authority (FCA, formerly Financial Services Authority) to act as intermediaries in investment activities. Hence, brokers also act as agents for their employers in carrying out agreed trading/investment duties on behalf of the firm.

This dual agency role can lead to conflicts of interest or 'ethical pollution' because the most profitable strategies (beneficial to the firm and individual brokers) may not always be the best solution for the client (Angel \& McCabe 2012). In order to prevent harming clients' interests, and ensure the integrity and smooth functioning of the markets, the FCA monitors 
and regulates the activities of all firms to ensure compliance with its Code of Practice, published in the FCA Handbook (2013). The Code of Practice is issued under Section 64 of the Financial Service and Markets Act (2000). It states that all 'Approved Persons' (e.g. brokers and their firms) must act with integrity, due care, skill and diligence, and they must observe proper standards of market conduct. Failing to pay 'due regard' to a client's interests deliberately, or without good reason, constitutes a breach of the Code. Furthermore, there is an obligation to treat customers fairly and to refrain from practices that could be reasonably expected to be detrimental to the client.

In addition to these broad principles, firms and their employees are also subject to more specific standards governing market activities as published in the FCA's Code of Market Conduct (also in the Handbook and based on Section 118 of the Financial Services and Markets Act 2000). Of particular relevance to the client-broker relationship and clients' interests, brokers are obliged to disclose all pricing information for each trade that they undertake (Macey and O'Hara 1997). In other words, they should buy (sell) securities at the lowest (highest) price during the trading horizon. ${ }^{\mathrm{i}}$ This is due to the fact that ever since the LSE became a competitive dealership system in 1986, the exchange is obliged to report real time quotes and trade information to the public. The Security and Investment Board (1995) distinguishes between the reporting of trades and their publication. All trades are reported to the exchange with immediate effect but are not necessarily published. Note also that "immediate" refers to within five minutes prior to execution to three minutes post the implementation of the trade LSE (2001). The availability of this information is intended to ensure brokers undertake trades on behalf of their clients at prices that were at least as good as those broadcast by the LSE. The price that is at least as good as could be obtained elsewhere is known as the 'best execution price', and brokers have an agency obligation to provide this to clients (Angel \& McCabe 2012). 


\section{Brokers' ethics in financial trading}

From our brief overview of the regulatory framework in the preceding section, it might be reasonable to assume that brokers, as employees (and presumed loyal agents) of firms that are bound by industry codes and regulation, always act in accordance with their obligations, and hence also in the best interests of their clients. Any malpractice might therefore be viewed as the result of systemic ethical deficiencies. However, even assuming optimal ethical guidance, research indicates that espoused organizational values are generally a poor predictor of how employees actually behave (Meglino \& Ravlin 1998), and the mere existence of ethical codes and/or law is not sufficient to guarantee employee ethical awareness or behaviour (Rottig et al. 2011, Di Lorenzo 2007). While an employee's decisions, beliefs and actions can be significantly influenced by industry/institutional factors (e.g. regulation) and organizational factors including ethical policies and culture (for a review see Craft 2012), such contextual 'artefacts' do not make the employee's decisions for him/her (Velasquez 2002). Institutional and organisational level influences interact with personal factors (i.e. individual differences) to shape an employee's perception of ethical standards and, in turn, his/her conduct (Singh 2011). Ultimately, employees are autonomous moral actors with responsibility for their own (un)ethical choices and actions (Velasquez 2002). Hence, even in a well-regulated industry brokers' decisions may sometimes lead to actions that do not optimally serve their clients' interests (Battalio \& Loughran 2008).

Brokers' (un)ethical conduct, in particular the pursuit of self-interest above the interests of their clients, is an issue that has attracted prior research interest in the business ethics literature. A recent study undertaken by Battalio and Loughran (2008) using data from the New York Stock Exchange showed that the main objective of brokers was to maximize their profits rather than the wealth of their clients. Indeed, as Baker and Veit (1998: 917) noted, 'investment professionals often face situations in which they can benefit personally at 
the expense of their clients by engaging in unethical behavior'. Trading with, or communicating, insider information is perhaps the most debated ethical violation (see for example Moore 1990), although not necessarily the most frequently occurring (Veit \& Murphy 1996). For example, Veit and Murphy (1996) found that almost $43 \%$ of brokers in U.S. had observed 'front running' in their brokerage firms (making personal trades before trading on behalf of the client), and there was a common perception that not all clients were dealt with 'fairly' when making investment decisions.

More recently, Norberg (2009) conducted in-depth interviews with Swedish stockbrokers, traders and market makers and concluded that most believed that they 'ought to look for personal advantages' (Norberg 2009: 218) when conducting trades. Consistent with this, brokers have been found to alter their trading strategies (e.g. their degree of risk taking) depending on whether they have achieved their bonus targets (Willman et al. 2002). Additionally, brokers are motivated to engage in excess (i.e. noise and/or unauthorised) trading in order to support future profit-making, and sometimes simply to alleviate boredom (Willman et al. 2006). Taken together, existing evidence suggests that, despite the clear frameworks governing the finance industry in the UK and elsewhere, brokers may sometimes prioritise their short and long-term self-interest over the interests of their clients. This decreases the wealth of investors and raises questions of brokers in relation to the fulfilment of their ethical duties as the client's agent.

Attempts to understand the ethical motivations and conduct of brokers have focused on the role of various individual differences and contextual influences. For example, Abdolmohammadi and Sultan (2002) found that people with higher levels of ethical reasoning, or cognitive moral development (Kohlberg 1981), were less likely to make use of insider information when trading stock in a simulated competitive market. In another simulation study, Hofmann et al. (2008) demonstrated that, controlling for profit, ethical 
investment decisions were influenced by participants' utility of morality (i.e. value placed on ethicality) and the moral intensity (Jones 1991) or strength of the ethical issues associated with an investment. Supporting these findings outside of the laboratory, Norberg (2009) found that stock brokers and traders did not view morality/ethics and an end in itself. Moreover, they regarded investment transactions as akin to a computer game, and being thus psychologically remote from the subjects of their actions they gave little thought to the wider consequences of their investment decisions.

According to Lilley and Lightfoot (2006) it is the hypercompetitive context of stock market trading that shapes the nature of an individual's 'trading self'. Specifically, performance targets based on profit generation, bonuses that are tied to their achievement, and the macho culture of 'star traders' on the trading floor, all combine to drive extreme levels of competition between traders. Essentially trading can be viewed as 'a continuous contest for wealth' (Abolofia, 1996a, cited in Lilley \& Lightfoot 2006: 384) and only winning this contest is good enough (Lilley \& Lightfoot 2006). From this perspective, stock market trading is largely about proving one's self-worth through profit-making, leaving little room for ethical considerations, including acting in clients' best interests.

In an effort to overcome such conflicts of interest and bolster compliance with the industry's regulatory framework, many firms have introduced their own corporate codes of ethics. While much has been written about the utility of corporate ethical codes, one of the key determinants of their effectiveness in regulating employee behaviour is how they are perceived and the degree to which they are accepted by the intended recipients / users (see Schwartz 2004, Singh 2011). Norberg (2009: 218) found that many brokers and traders viewed ethics as the 'adversary of a rational and efficient market', and some believed that the introduction of ethical codes would constrain the invisible hand of the market, thereby 
undermining the overall effectiveness of financial markets. The question is: are brokers' apparently egoist motivations and the invisible hand sufficient to protect investors' interests?

It is a common misinterpretation of egoism (as an ethical justification for behaviour) that any pursuit of self-interest in business and economic contexts is morally permissible (Bragues 2009). However, an important caveat to Adam Smith's formulation of egoism is that the pursuit of individual self-interest is ethical only when the invisible hand in free market economies ensures (e.g. via perfect competition) that the greater social good is ultimately served (Bishop 1995). In the case of the financial markets, the competitiveness of the stock exchange is typically impaired by inter alia information asymmetry, lack of transparency and inequalities in the abilities of investors to access alternative brokers if a commissioned broker fails to maximize returns (Battalio \& Loughran 2008). Hence brokers' pursuit of profit will not necessarily be translated into ethical outcomes (i.e. maximum utility for investors) because the invisible hand cannot function effectively under these less than ideal conditions.

The evidence reviewed suggested that, despite clearly articulated obligations, brokers and traders are primarily self-interested; they see little need for ethics in trading, and are resistant to the introduction of corporate ethical codes. Brokers prefer instead to entrust the invisible hand with the ethical distribution of wealth (Norberg 2009). In the light of this, we argue that altering the mechanisms for executing transactions in the financial markets may constitute a more effective (and acceptable) means of aligning brokers' and investors' interests than imposing additional ethical standards and/or regulation alone. In other words, if brokers' self-interested actions are to result in more consistently ethical outcomes (i.e. increasing investor wealth), a more competitive system of trading is needed. The introduction of the computerized limit order trading system into international equity markets offers an opportunity to test this proposition. 


\section{Liquidity in financial markets}

In this section we provide an overview of the basic mechanisms of the financial markets and the different systems - quote versus limit order systems - by which stocks are traded. One of the most critical factors that investors look for in a financial market is liquidity. Liquidity is defined as the ability to trade stock rapidly with little price impact. Because investors' 'buy' orders often do not coincide with corresponding 'sell' orders, liquidity in the stock exchanges is maintained using market makers (Angel \& McCabe 2013). In the UK, market making is undertaken by FCA-authorised firms that are willing to provide a financial market whenever investors wish to trade. In return for providing the financial market, market makers are granted monopoly rights by the stock exchange to post different prices for stock purchases and sales. As a result, market makers buy stock at the bid price and sell the stock at the higher ask (offer) price. This ability to buy the stock low and sell high is the market makers' compensation for providing the financial market. Their compensation (and profit) is derived from the ask price minus the bid price, which in turn is defined as the bid-ask spread. In essence, the market maker's business model involves accumulating individually small profits on a high volume of trades (Angel \& McCabe 2013).

Over the last decade there has been a long-standing debate among market practitioners, regulators and academics, on the relative merits of a quote driven dealer market verses order driven auction markets in international stock markets. In the active dealer market liquidity is provided by two-way (bid/offer) continuous quotes, offered by at least two competing market makers. In the order driven auction market the active dealer market continues to exist but in addition investors can compete directly with dealers and with each other through the submission of binding limit orders. The motivation behind the introduction of an auction market is that the inclusion of a limit order system into a market increases competition, which in turn increases market liquidity. ${ }^{\text {ii }}$ This is because liquidity is provided 
by two sources: the competing dealers or market makers and the public investors, given that they are allowed to post limit orders. It is for this reason that electronic limit order trading systems have been sweeping international equity markets around the world in the last decade. The empirical evidence based upon highly traded liquid stocks provides substantial evidence that electronic computerized trading systems enhance market liquidity. Naik and Yadav (2004) found that liquidity is significantly increased for FTSE 100 stocks which account for approximately $80 \%$ of total trading volume in the LSE, once they are traded on an electronic limit order trading system. ${ }^{\text {iii }}$

Barclay et al. (1999) documented that liquidity has risen on the NASDAQ following the introduction of the electronic trading system. ${ }^{\text {iv }}$ Domowitz (2002) found, in a sample of 42 countries, that a screen system increases market liquidity by reducing trading costs and increasing trading volume. Jain (2003) found that the empirical findings of Domowitz (2002) hold for institutional trades for 51 countries.

However, it has been established that the electronic limit order book system is not the optimal trading mechanism for thinly-traded illiquid stocks. Kairys et al. (2000) and Lauterbach (2001) reported that the movement from call to continuous trading on the Riga Stock Exchange and the Tel-Aviv Stock exchange respectively resulted in increased liquidity of most liquid stocks and depressed the thinly traded stocks. Theissen (2002) demonstrated that floor trading on the German Stock Exchange offers more liquidity than screen trading for moderately less liquid stocks. Nimalendran and Petrella (2003) reported that the transition from a pure limit order system, to a hybrid system with at least two competing market makers on the Italian Stock Exchange, increased the liquidity of thinly-traded stocks. Lai (2007) analysed the impact of liquidity for the moderately liquid stocks listed on the FTSE 250 that account for approximately $16 \%$ of total trading volume on the LSE. He showed that the liquidity of the stocks dropped substantially after the introduction of the limit order book. 
The primary reason for the poor performance of the limit order book for illiquid stocks is information asymmetry. Benveniste et al. (1992) and Snell and Tonks (2003) theoretically show that market makers are superior in resolving information asymmetry than the order book system. Easley et al. (1996) and Theissen (2002) provided empirical evidence suggesting that information asymmetry is of more importance in less liquid stocks. This is because they find that the probability of information-based trading is higher for low volume stocks in the US and German equity markets, respectively.

To summarise, ethical concerns have been raised in both the academic and public domains about the extent to which brokers may prioritise their own profits at the expense of benefiting their clients. We argue that structural improvements in the stock exchange trading systems may offer an effective means, beyond the use of formal ethics management systems (e.g. ethical codes), for better aligning broker and client interests. The aim of the present research is therefore to investigate whether the introduction limit order trading enhances the wealth of the investor. To this end, we examine the proportion of total trades executed at the best execution price for various indices listed on the LSE before and after they were available on an electronic limit order trading system. ${ }^{\mathbf{v}}$

\section{Method}

\section{Research context: Trading mechanism on the London Stock Exchange}

In response to increased competition, the LSE implemented an electronic order-matching system, SETS (Stock Exchange Electronic Trading System) on the $20^{\text {th }}$ October 1997 for FTSE 100 stocks. The FTSE 100 stocks consist of the largest 100 firms listed on the LSE by full market value and account for approximately $80 \%$ of total trading volume on the LSE. The launch of SETS represented an important switch from quote driven to order driven market structures. The new order driven system replaced the SEAQ (Stock Exchange 
Automated Quotation) trading system. Under the SETS trading system, the LSE replaced obligated market makers with voluntary dealers, and allowed the public to compete directly with dealers in these stocks through the submission of limit orders. ${ }^{\mathrm{vi}}$

Initially, the SETS trading system was only applicable to the FTSE 100 index. However, through time the LSE allowed more liquid stocks to be traded in the system, included stocks that have since become constituents of the FTSE 100, the FTSE 100 reserve list and companies that have been delisted from the FTSE 100 list after $20^{\text {th }}$ October 1997 . In addition, companies with individual equity options traded on the London International Financial Futures and Options Exchange (LIFFE) can also be traded in the SETS trading system.

The LSE has long considered expanding the realm of SETS into less liquid stocks. This became apart when on 5th September 1999 the moderately liquid FTSE 250 index began trading on the SETS trading system. ${ }^{\text {vii }}$ Recently, the LSE developed the SETSmm platform, where in order to motivate the trading of stocks with low liquidity, post limit orders are exempt from the exchange tariffs, meaning that the cost of trading is reduced. In December 2005, the LSE evaluated the possibility of introducing FTSE Aim Index securities on the SETSmm trading system. The FTSE Aim Index is widely regarded as the most illiquid index in the LSE, given that it consists of companies quoted on the Alternative Investment Market, a sub market of the LSE that allows smaller companies to float shares with a more flexible regulatory system. ${ }^{\text {viii }}$ On $5^{\text {th }}$ December 2005 the securities listed on the FTSE Aim Index with respect to market capitalization started trading on the SETSmm system.

An advantage of conducting our empirical analysis across different regimes of stock market liquidity is that they represent a good approximation of trading costs. ${ }^{\text {ix }}$ Trading costs are an important determinant of whether or not customers employ the services of a broker. This is because if brokers can obtain either a more competitive price than the exchange, or a 
cheaper trade (by paying a lower bid-ask spread due to the high volume of trades undertaken), investors will make higher returns, thereby justifying the employment of the broker (Wall Street Journal, 1993).

\section{Data collection and analysis}

We obtained data from the LSE on all trades undertaken on the FTSE 100, FTSE 250 and FTSE Aim Index one year before and after they began trading on the electronic limit order trading system. ${ }^{\mathrm{x}}$ We computed the proportion of trades (in percentages) executed by brokers at the best execution price pre and post the announcement of limit order trading for each individual index in our sample. Because the analysis encapsulated trades on equities of different bid-ask spread values, we simultaneously captured the (lowest) price and approximate cost of each transaction executed on the LSE. These constitute two key elements of best execution and, in turn, client utility. ${ }^{\mathrm{xi}}$ Asymptotic t-statistics, in which standard errors were obtained from a bootstrap simulation involving 10,000 replications, were calculated to test for the significance of any differences between pre and post limit order trading.

\section{Findings}

The results of the proportion of total trades executed by individual brokers on the FTSE 100, FTSE 250 and FTSE Aim Index at the best execution price pre and post the availability of the electronic limit order trading system can be seen in Table 1. Overall, there were significant increases in the proportion of trades undertaken at the best execution price for all indices following the introduction of limit order trading. For the FTSE 100, 56\% of the trades were executed at the best execution price after limit order trading versus $43 \%$ before the limit order trading period. The asymptotic $\mathrm{t}$ statistic for the difference in estimates is equal to 9.72 , which is significant at the $5 \%$ level. We also found that the proportion of trades undertaken 
at the best execution price significantly increased for the FTSE 250 (44\% post the limit order period) relative to the pre limit order trading period (35\%). The increase is significant with an asymptotic t-statistic of 4.17 . Finally, the proportion of trades undertaken at the best execution price was significantly enhanced for the FTSE Aim index during the post limit order trading period $(22 \%)$ relative to the pre limit order trading period $(15 \%)$ with an asymptotic t statistic of 3.21. ${ }^{\mathrm{xii}}$

\section{[Insert Table 1 here]}

\section{Discussion}

The aim of this research was to explore whether the introduction of electronic limit order trading systems led to greater maximization of investor wealth, and indirectly supported more ethical trading behaviours by brokers. The main contribution of the present study is in highlighting the importance of market structures as a means of enhancing outcomes for investors. In line with expectations, our findings suggest that the additional liquidity induced by the limit orders, forces brokers to reduce their profit margins by executing a higher proportion of trades at the best execution price, resulting in increasing the wealth of investors, and smaller profits for brokers, regardless of firm size. In ethical terms, these findings imply that, to the extent that the introduction of electronic limit order systems into the market increases competition, the outcomes of brokers' self-interest becomes more closely aligned with stakeholder interests. Under the conditions created by limit order trading it appears that the utility of investors is increased, even if brokers are motivated to maximize their own selfinterest. Hence, the limit order system may help convert brokers' individualistic (i.e. egoist) motivations into investor wealth by providing a more effective mechanism (driven by 
informational transparency and liquidity) through which the 'invisible hand' of the market is supported.

We can also obtain an explanation of our results from the market microstructure literature. Specifically, market makers are faced with two types of traders: liquidity traders and informed traders. Informed traders trade because they have private information not reflected in prices, whereas liquidity traders trade for reasons other than superior information. Market makers sustain losses from trading with informed traders and they recover these losses through the bid-ask spread. Therefore, the greater the information asymmetry between trades and market makers the wider the bid-ask spread (Kim \& Verrecchia 1994). In addition, the market maker also gets compensated for two other cost components, the inventory holding and order processing cost component. The inventory cost is defined as the compensation provided to the market maker for holding an undiversified portfolio as a result of creating the financial market. The order processing component compensates the market maker for the cost of processing orders, involving labour, communication, clearing and record keeping expenses.

The announcement of the limit order trading period should increase the trading volume of all indices at the time of the news. ${ }^{\text {xiii }}$ On the one hand, the higher trading volume presents the market maker with economies of scale suggesting that the bid-ask spread should fall (Copeland \& Galai 1983). In addition, we would expect that the order processing component declines during the limit order trading period due to the negative empirical relationship between trading volume and the order processing cost (e.g. Madhaven et al. 1997). On the other hand, increased volatility exposes the market maker to greater risk of dealing with investors with superior information and of holding an undiversified portfolio, suggesting that the bid-ask spread should increase. Our results indicate that the former dominates the latter effect during limit order trading announcements. Overall, our empirical 
evidence shows that as a result of the increase in trading volume associated with the announcement of the limit order trading periods for the FTSE 100, FTSE 250 and FTSE Aim indices, market makers are reducing their bid-ask spreads. This rise in liquidity and the transparency in the limit order trades, increases the proportion of total trades executed by brokers at the best execution price. ${ }^{\text {xiv }}$ Therefore, the announcement of limit order trading on the LSE has improved the quality of the exchange, which in turn has enhanced the wealth of investors.

A limitation of the present study is that we did not have access to data concerning the volume (amount) of shares that were traded. It would be beneficial to observe if our results change when we partition the data into large and small trades. It may be that brokers are more effective in achieving the best execution price for large trades given the lack of liquidity in the market. This is why specialist brokers are often used for large transactions (see among others, Madhavan and Cheng 1997). A related limitation is that our data did not allow for a more nuanced operationalization of best execution price. While we captured price, and cost of trade by proxy, best execution could be more precisely measured as the trade with the lowest total cost after factoring in trade volume, brokers' costs, currency conversion (where relevant), and probability of failure. These shortcomings offer an interesting avenue for future research that would make a useful extension to the present findings.

It is also notable that the increased proportion of trades undertaken at the best execution price' in the present study still leaves room for improvement. Above and beyond the uncertainties of the international equity markets, it is important to recall that traders' apparently egoistic pursuit of profit, as found in previous research, is shaped not only by the situational context of the markets but also by organisational systems and individual differences. In interviews with traders and their managers, Willman et al. (2002) found that managers generally only intervened in trades when losses were occurring - establishing a 
monitoring regime that controlled losses but did not encourage maximization of investor returns. In addition, some traders may be more likely than others to pursue personal goals; for example, traders with a higher illusion of control (Langer 1975) conduct more frequent and riskier trades (Willman et al. 2002). Therefore, in addition to structural changes that enhance liquidity and transparency in trading systems, further maximization of investors' wealth might be achieved through attention to broker recruitment and selection, and organisational leadership processes.

First, however, further research is needed to establish more precisely what proportion of variance in brokers' conduct is accounted for by the various influencing factors that can shape trading decisions. The key strength of the present study is the longitudinal nature of the data. However, we did not directly measure behavioural variables, nor did we collect firmlevel information relating to ethical policies. Future research could therefore usefully explore the multi-level associations between trading systems, and institutional (e.g. FCA), organisational and individual factors (including brokers' ethical orientations) in influencing brokers' trading strategies and performance. This would enable the design of more holistic solutions that support ethical conduct and client interests.

\section{Conclusion}

The maintenance of trust between brokers and their clients is of paramount importance for the viability of financial markets, and is dependent on brokers fulfilling their moral obligations to maximize investors' wealth. In this paper we therefore revisited the issue of the (un)ethical trading behaviours of stock brokers in light of the global transformation of financial markets from quote to order driven systems. Using evidence from the LSE we found significant evidence of a substantial increase in the proportion of trades undertaken by stock brokers on behalf of their clients executed at the best execution price. Our results remain intact across all 
firm sizes within the LSE. We conclude that the announcement of limit order trading increases the wealth of investors because of an enhancement in the quality of the LSE - in other words, in spite of (rather than because of) the ethical intentions or behaviours of brokers. Given the importance of ensuring that the ethical behaviour of brokers is aligned with their agency responsibilities to investors, and the fact that electronic limit order trading systems have been sweeping international equity markets around the world in the last decade, the findings and implications of this study are significant. In short, trading structures that improve the competitiveness of the market via greater liquidity and transparency may to some degree complement existing ethical management practices and regulation. Limit order trading systems in particular may offer an ethical safeguard that reduces harm and increases benefits for investors, by facilitating the 'invisible hand' of the market. 


\section{References}

Abdolmohammadi, M. and Sultan, J. 2002. 'Ethical reasoning and the use of insider information in stock trading.' Journal of Business Ethics, 37:2, 165-173.

Angel, J.J. and McCabe, D. 2012. 'Ethical standards for stockbrokers: Fiduciary or suitability?' Journal of Business Ethics, Advance on-line, DOI 10.1007/s10551-0121362-y.

Angel, J.J. and McCabe, D. 2013. 'Fairness in financial markets: The case of high frequency trading.' Journal of Business Ethics, 112:4, 585-595.

Baker, H.K. and Veit, E.T. 2008. 'A comparison of ethics of investment professionals: North America versus Pacific Rim nations.' Journal of Business Ethics, 17:8, 917-937.

Barclay, M.J, Christie, W.G., Harris, J.H., Kandel E. and Schultz. P.H. 1999. 'The effects of market reform on the trading costs and depths of Nasdaq stocks.' Journal of Finance, 54: 1, 1-34.

Battalio, R.H, and Loughran, T. 2008. 'Does payment for order flow to your broker help or hurt you?' Journal of Business Ethics, 80:1, 37-44.

BBC. 2012. 'Barclays fined for attempts to manipulate Libor rates.' http://m.bbc.co.uk/news/business-18612279, last accessed 3/7/2012.

Benveniste, L.M.A, Marcus, J. and Wilhelm, W.J. 1992. 'What's special about the specialist?' Journal of Financial Economics, 32:1, 61-86.

Bishop, J.D. 1995. 'Adam Smith's invisible hand argument.' Journal of Business Ethics, $14: 3,165-180$.

Bragues, G. 2009. 'Adam Smith's vision of the ethical manager.' Journal of Business Ethics, 90:4, 447-460.

Copeland, T. and Galai, D. 1983. 'Information effects on the bid-ask spread.' Journal of Finance, 38:5, 1457-1469. 
Craft, J.L. 2012. 'A Review of the Empirical Ethical Decision-Making Literature:

2004-2011'. Journal of Business Ethics, Advance on-line, DOI 10.1007/s10551-0121518-9.

Di Lorenzo, V. 2007. 'Business ethics: Law as a determinant of business conduct.' Journal of Business Ethics, 71:3, 275-299.

Domowitz, I. 2002. 'Liquidity, transaction costs, and re-intermediation in electronic markets.' Journal of Financial Services Research, 22:1-2, 141-157.

Easley, D, Kiefer, N.M., O’Hara M. and Paperman, J.B. 1996. 'Liquidity, information, and infrequently traded stocks.' Journal of Finance, 51:4, 1405-1436.

FCA. 2013. Financial Conduct Authority Handbook. On-line, http://www.fshandbook.info/FS/html/FCA, last accessed 27/4/2013.

Financial Service and Markets Act. 2000. On-line, http://www.legislation.gov.uk/ukpga/2000/8/contents, last accessed 27/4/2013.

Hofmann, E., Hoelzl, E. and Kirchler, E. 2008. 'A comparison of models describing the impact of moral decision making on investment decisions.' Journal of Business Ethics, 82:1, 171-187.

Jain, P.K. 2003. 'Institutional design and liquidity at stock exchanges around the world'. Manuscript, University of Memphis.

Jones, T.M. 1991. 'Ethical decision making by individuals in organizations: An issue contingent model.' Academy of Management Review, 16:2, 366-95.

Kairys, J.P, Kruza, J.R. and Kumpins, R. 2000. 'Winners and losers from the introduction of continuous variable price trading: Evidence from the Riga stock exchange.' Journal of Banking and Finance, 24:4, 603-624.

Kim, O. and Verrecchia, R. E. 1994. 'Market liquidity and volume around earnings announcements.' Journal of Accounting and Economics, 17:1-2, 41-67. 
Kohlberg, L. 1981. Essays in Moral Development: The Philosophy of Moral Development San Francisco: Harper \& Row.

Krinsky, I. and Lee, J. 1996. 'Earnings announcements and the components of the bid-ask spread.' Journal of Finance, 51:4, 1523-1535.

Lai, H. 2007. 'The market quality of dealer versus hybrid markets: The case for moderately liquid securities.' Journal of Business Finance and Accounting, 34:1-2, 349-373.

Langer, E.J. 1975. 'The illusion of control.' Journal of Personality and Social Psychology, $32: 2,311-328$.

Lauterbach, B. 2001. 'A note on trading mechanism and securities' value: The analysis of rejects from continuous trade.' Journal of Banking and Finance, 25:2, 419-430.

Lilley, S. and Lightfoot, G. 2006. 'Trading narratives.' Organization, 13:3, 369-391.

London Stock Exchange. 2001. Quality of Markets Quarterly Review, Spring, 18.

Macey, J and O'Hara, M. 1997. 'The law and economics of best execution.' Journal of Financial Intermediation, 6:3, 188-223.

Madhavan, A., and M.Cheng. 1997. 'In search of liquidity: Block trades in the upstairs and downstairs markets', Review of Financial Studies, 10:1, 175-204.

Madhaven, A., Richardson, M. and Roomans, M. 1997. 'Why do security prices change? A transaction-level analysis of NYSE stocks.' Review of Financial Studies, 10:4, 10351064.

Meglino, B.M. and E.C. Ravlin. 1998. 'Individual values in organizations: Concepts, controversies, and research.' Journal of Management, 24:3, 351-389.

Moore, J. 1990. 'What is really unethical about insider trading?' Journal of Business Ethics, $99: 3,171-82$. 
Naik, N. and Yadav, P.K. 2004. 'Trading costs of public investors with obligatory and voluntary market-making: Evidence from market reforms.' Manuscript, London Business School.

Nimalendran, M. and Petrella, G. 2003. 'Do thinly-traded stocks benefit from specialist intervention?' Journal of Banking and Finance, 27:9, 1823-1854.

Norberg, P. 2009, 'I don't care that people don't like what I do - Business codes viewed as invisible or visible restrictions.' Journal of Business Ethics, 86:2, 211-225.

Rottig, D., Koufteros, X. and Umphress, E. 2011. 'Formal infrastructure and ethical decision making: An empirical investigation and implications for supply management'. Decision Sciences, 42:1, 163-204.

Schwartz, M.S. 2004. 'Effective corporate codes of ethics: Perceptions of code users.' Journal of Business Ethics, 55:4, 323-343.

Securities and Investment Board. 1995. Regulation of the United Kingdom Equity Markets, June, London: Securities and Investment Board.

Singh, J.B. 2011. 'Determinants of the effectiveness of corporate codes of ethics: An empirical study.' Journal of Business Ethics, 101:3 385-395.

Snell, A. and Tonks, I. 2003. 'A theoretical analysis of institutional investors' trading costs in auction and dealer Markets.' Economic Journal, 113:489, 576-597.

Smith, A. 1981 [1776]. An Inquiry into the Nature and Causes of the Wealth of Nations, Volume 1. Indianapolis, IN: Liberty Fund.

Thiessen, E. 2002. 'Floor versus screen trading: Evidence from the German stock market.' Journal of Institutional and Theoretical Economics, 158:1, 32-54.

Velasquez, M. 2002. Business Ethics: Concepts and Cases. ( $5^{\text {th }}$ Ed). New Jersey: Prentice Hall. 
Veit, E.T. and Murphy, M.R. 1996. 'Ethics violations: A survey of investment analysts.' Journal of Business Ethics, 15:12, 1287-1297.

Wall Street Journal. 1993. 'How Wall Street turns trades into gold', Wall Street Journal.

Willman, P., Fenton-O’Creevey, M., Nicholson, N. and Soane, E. 2006. 'Noise trading and the management of operational risk: Firms, traders and irrationality in financial markets.' Journal of Management Studies, 43:6, 1357-1374.

Willman, P., Fenton-O’Creevey, M., Nicholson, N. and Soane, E. 2002. ‘Traders, management behaviour and loss aversion in investment banking: A field study.' Accounting, Organisations and Society, 27:1-2, 85-98. 


\section{Table 1}

\section{Proportion of Trades Executed at the 'Best Price' around Limit Order Trading}

\section{Announcements on the London Stock Exchange}

\begin{tabular}{lcccc}
\hline Index & Event Date & Pre Event Period & Post Event Period & Event Less Pre \\
\hline FTSE 100 & $20 / 10 / 97$ & $43 \%$ & $56 \%$ & $13 \%(9.72)^{*}$ \\
FTSE 250 & $05 / 09 / 99$ & $35 \%$ & $44 \%$ & $9 \%(4.17)^{*}$ \\
FTSE Aim Index & $05 / 12 / 05$ & $15 \%$ & $22 \%$ & $7 \%(3.21)^{*}$ \\
\hline
\end{tabular}

Note: Proportion of trades calculated in percentages executed at the 'best execution price' by individual brokers on the London Stock Exchange were computed for the pre and post limit order trading period for the FTSE 100, FTSE 250 and FTSE Aim Index. The limit order trading period consists of a one year trading interval of all trades undertaken by individual brokers at the 'best execution price' after the limit order announcement for each index in our sample on the London Stock Exchange. The pre limit order trading period consists of a one year trading interval of all trades undertaken by individual brokers at the 'best execution price' before the limit order announcement for each index in our sample on the London Stock Exchange. Asymptotic t-statistics where standard errors are obtained from a bootstrap simulation involving 10,000 replications are shown in the round brackets.* significant at the $5 \%$ level. 


\section{Notes}

i Note the trading horizon for each individual trade is decided between the investor and the individual broker before any trading has taken place.

ii A limit order trade is an obligation that an investor undertakes to trade a fixed number of shares when the price of the asset reaches a certain point over a particular time interval.

iii According to the Secondary Market Fact sheet issued by the LSE in September 2007, the FTSE 100 stocks represent approximately $80 \%$ of the entire trading volume on the LSE.

iv Note in the NASDAQ dealers are obliged to quote two-way prices as they did prior to the electronic trading system whereas, in the LSE the participation of market makers is entirely voluntary.

${ }^{\vee}$ We undertake the empirical analysis on different equity indices within the LSE to evaluate the impact of firm size on the behaviour of traders, given that indices are constructed on the market capitalization of firms.

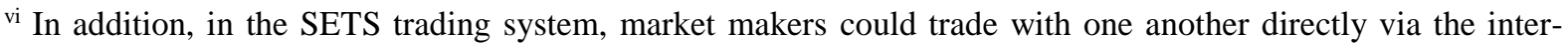
dealer broker system.

vii The FTSE 250 is the capitalization weighted index of the $101^{\text {st }}$ to $350^{\text {th }}$ largest company on the LSE.

viii The FTSE Aim Index is highly illiquid with average bid-ask spreads of 5-12\% of share price whereas, FTSE 250 and FTSE 100 Indices are highly liquid indices with average spreads of around $2.5 \%$ and $1 \%$ of share price, respectively.

ix There is a direct correlation between the bid-ask spread and trading costs. This is because when bid-ask spreads change the costs are carried over to the customers.

${ }^{\mathrm{x}}$ To increase robustness we also looked at trades three and six months before and after they began trading on the limit-order trading system for the FTSE 100, FTSE 250 and FTSE Aim Index. The results are quantitatively similar and are available from the authors upon request.

${ }^{x i}$ We would like to thank an anonymous reviewer for suggesting that brokers are employed for both their ability to obtain the best and cheapest execution price of a trade.

xii Asymptotic t-statistic standard errors are obtained from a bootstrap simulation involving 10,000 replications for each individual index. The bootstrap algorithms are available from the authors upon request.

xiii Krinsky and Lee (1996) point out that any event conveying price-relevant information with predictable timing increases trading volume.

xiv The limit order trades are transparent to all investors on the electronic trading system. 